\title{
Normal Flora
}

National Cancer Institute

\section{Source}

National Cancer Institute. Normal Flora. NCI Thesaurus. Code C125957.

Harmless or beneficial population of microorganisms or plant life that normally occur in specific areas of the body or the environment. 